\title{
Diabetes self-management education improves quality of care and clinical outcomes determined by a diabetes bundle measure
}

This article was published in the following Dove Press journal:

Journal of Multidisciplinary Healthcare

2I November 2014

Number of times this article has been viewed

\author{
Kimberly D Brunisholz ${ }^{1,2, *}$ \\ Pascal Briot ${ }^{1,2, *}$ \\ Sharon Hamilton' \\ Elizabeth A Joy ${ }^{3}$ \\ Michael Lomax ${ }^{2}$ \\ Nathan Barton ${ }^{2}$ \\ Ruthann Cunningham ${ }^{3}$ \\ Lucy A Savitz ${ }^{2}$ \\ Wayne Cannon' \\ 'Primary Care Clinical Program, \\ Intermountain Healthcare, Salt \\ Lake City, UT, USA; ${ }^{2}$ Institute for \\ Healthcare Delivery, Intermountain \\ Healthcare, Salt Lake City, UT, USA; \\ ${ }^{3}$ Office of Research, Intermountain \\ Healthcare, Salt Lake City, UT, USA \\ *Joint first authors
}

Correspondence: Kimberly D Brunisholz Primary Care Clinical Program, Institute for Healthcare Delivery, Intermountain Healthcare, 36 South State Street, Salt Lake City, UT 84III, USA Tel +l 80I 4423912

Email kim.brunisholz@imail.org
Purpose: The purpose of this study was to determine the impact of diabetes self-management education (DSME) in improving processes and outcomes of diabetes care as measured by a five component diabetes bundle and $\mathrm{HbA}_{1 \mathrm{c}}$, in individuals with type 2 diabetes mellitus (T2DM).

Methods: A retrospective analysis was performed for adult T2DM patients who received DSME training in 2011-2012 from an accredited American Diabetes Association center at Intermountain Healthcare (IH) and had an $\mathrm{HbA}_{1 \mathrm{c}}$ measurement within the prior 3 months and 2-6 months after completing their first DSME visit. Control patients were selected from the same clinics as case-patients using random number generator to achieve a 1 to 4 ratio. Case and control patients were included if 1) pre-education $\mathrm{HbA}_{1 \mathrm{c}}$ was between $6.0 \%-14.0 \%$; 2) their main provider was a primary care physician; 3 ) they met the national Healthcare Effectiveness Data and Information Set criteria for inclusion in the IH diabetes registry. The IH diabetes bundle includes retinal eye exam, nephropathy screening or prescription of angiotensin converting enzyme or angiotensin receptor blocker; blood pressure $<140 / 90 \mathrm{mmHg}$, LDL $<100 \mathrm{mg} / \mathrm{dL}, \mathrm{HbA}_{\mathrm{lc}}<8.0 \%$.

Results: DSME patients had a significant difference in achievement of the five element $\mathrm{IH}$ diabetes bundle and in $\mathrm{HbA}_{1 \mathrm{c}}$ \% compared to those without DSME. After adjusting for possible confounders in a multivariate logistic regression model, DSME patients had a 1.5 fold difference in improvement in their diabetes bundle and almost a 3 fold decline in $\mathrm{HbA}_{1 \mathrm{c}}$ compared to the control group.

Conclusion: Standardized DSME taught within an IH American Diabetes Association center is strongly associated with a substantial improvement in patients meeting all five elements of a diabetes bundle and a decline in $\mathrm{HbA}_{1 \mathrm{c}}$ beyond usual care. Given the low operating cost of the DSME program, these results strongly support the value adding benefit of this program in treating T2DM patients.

Keywords: diabetes, type 2 diabetes, $\mathrm{HbA}_{1 \mathrm{c}}$, bundle, diabetes education, DSME

\section{Introduction}

Diabetes is a major cause of morbidity, disability, and mortality, affecting over 27 million persons in the United States. ${ }^{1}$ The World Health Organization has predicted a global increase in diabetes prevalence of 39\% between the years 2000 and 2030, reflecting an increase of 366 million people by the year $2030 .{ }^{2}$ In the United States, in 2007 , the cost of diabetes was $\$ 174$ billion, roughly $10 \%$ of total health care expenditures ${ }^{3}$ and by 2030 , health care spending on diabetes is projected to reach $\$ 860$ billion. ${ }^{4}$ An enormous opportunity for quality improvement and cost reduction lies within identifying pragmatic interventions that are effective in the management of diabetes, yet, are sustainable and create value from the point of view of the patient, clinician, and delivery system. 
Intermountain Healthcare (IH) is a not-for-profit integrated delivery system in Utah and Idaho that has a network of 22 hospitals and 185 clinics providing more than half of all health care delivered in the region. ${ }^{5}$ Since 2010, primary care practices have focused on improving the management of diabetes by implementing best-practice guidelines, benchmarking against other health care institutions, and reporting adherence to an all-or-none five elements diabetes bundle (Table 1). The IH diabetes bundle is an internal measurement tool to gauge intermediate quality outcomes associated with diabetes. It was previously developed by an internal group of physician experts who thoroughly reviewed and considered the evidence. Bundle components were chosen if they were clinically meaningful and if they were indicators of quality care for patients with diabetes. Data systems were created to support measurement over time. The physician expert panel vetted the bundle components with medical and operational leadership, began collecting data to benchmark success, and developed a clinical board goal to make targeted improvements over the last 2 years. The IH diabetes bundle is an allor-none measurement and requires a patient to meet all five parts of the bundle within the last 12 months of care, except for a retinal eye exam which may be completed within the last 2 years. Meeting the diabetes bundle is one component of IH's 2013 primary care pay for performance incentive program.

Another strategy within IH clinics has been the deployment of team-based care via its mental health integration $(\mathrm{MHI})^{6}$ - integration of mental health into primary care - and personalized primary care (PPC) - IH's version of the national Patient-Centered Medical Home project. Both strategies have had a significant impact on improving patients' outcomes for diabetes especially with achievement of the diabetes bundle and lowering $\mathrm{HbA}_{1 \mathrm{c}}$, and are scheduled to be fully implemented across the system by early $2014 .^{7}$

Management strategies for diabetes have evolved to not only include appropriate medications, but also include guidelines that recommend diet, physical activity, and weight counseling. ${ }^{8-10}$ The effectiveness of diabetes education has

Table I Intermountain Healthcare's diabetes bundle definition

Diabetes bundle elements
$\mathrm{HbA}_{\mathrm{Ic}}<8.0 \%$
$\mathrm{LDL}-\mathrm{c}<100 \mathrm{mg} / \mathrm{dL}$
Retinal eye exam performed in the last 2 years
Nephropathy screening through microalbumin testing or be prescribed
an ACEi or ARB medication
Documented blood pressure that is less than $140 / 90 \mathrm{mmHg}$

Abbreviations: ACEi, angiotensin-converting enzyme inhibitor; ARB, angiotensin II receptor. been well-established by clinical trials to demonstrate a beneficial effect on $\mathrm{HbA}_{1 \mathrm{c}}$ control, reduce complications and acute healthcare utilization, and subsequently, produce a reduction in the total cost of care to treat a diabetic patient. ${ }^{11-16}$ However, there is little evidence with respect to the effect of diabetes education on improved outcomes as assessed by a "diabetes bundle", where multiple aspects of diabetes care and process outcomes are rolled up into one measure. Diabetes self-management education (DSME) has emerged as a strategy to educate, engage, and empower patients to achieve control of their diabetes; reducing health care utilization and cost, while improving outcomes. To test the hypothesis that DSME is associated with improvements in both processes and outcomes of diabetes care, a retrospective study was performed utilizing patients found within the IH's diabetes registry.

\section{Methods}

A retrospective case-control study was conducted to evaluate the difference in IH five part diabetes bundle measure in patients who received DSME as compared to a control population from the same IH primary care practice who did not receive DSME during a similar time period. The primary outcome in this study was change in IH five part diabetes bundle measure performance before and after DSME. In addition, we evaluated the relationship between DSME and $\mathrm{HbA}_{1 \mathrm{c}}$ over time and the percentage of patients who had a decline in $\mathrm{HbA}_{\mathrm{lc}}$ over time.

\section{Study population}

IH's Enterprise Data Warehouse (EDW) was queried for all adult type 2 diabetes mellitus patients (18-75 years of age) between 2011-2012 who received DSME from one of five American Diabetes Association (ADA)-certified diabetes education centers housed within the IH delivery system, and who had an $\mathrm{HbA}_{1 \mathrm{c}}$ measurement within 0-3 months before and 2-6 months after their first DSME visit. Patients meeting these criteria were further delineated for study if: 1) they met the national Healthcare Effectiveness Data and Information Set definition for inclusion in the IH diabetes registry; ${ }^{17}$ 2) their main provider was a primary care provider within the IH medical group; and 3) they had a baseline $\mathrm{HbA}_{1 \mathrm{c}}$ of $6.0 \%-14.0 \%$. Similarly, a control population who did not receive DSME was selected from within the EDW system who met the criteria above during the same time period and from the same clinics that a case-patient was attributed to. Patients with missing clinical data (ie, diabetes bundle or $\mathrm{HbA}_{1 \mathrm{c}}$ measures) were excluded from the study. The study population was limited to patients whose main provider was a primary care physician employed by the medical group 
due to inconsistent data capture among affiliate practices and strong institutional support for primary care physicians who have been actively focused on improving the management of patients with diabetes. We eliminated all patients who had a baseline $\mathrm{HbA}_{1 \mathrm{c}}>14 \%$ because these outliers may be artifact of miscoded data or extreme instances of poor diabetes control. Because the control population available was much larger than the study population, a random number generator was utilized to randomly select patients within this group. It was determined a priori that a 1:4 ratio of cases to controls matched by baseline $\mathrm{HbA}_{1 \mathrm{c}}$ category $(6 \%-6.9 \% ; 7 \%-7.9 \%$; $8 \%-8.9 \%$ and $\geq 9.0 \%$ ) would be appropriate to detect a difference in an all-or-none bundle of diabetes measures over time assuming a power of $80 \%$ and an alpha of 0.05 . This study was approved by the IH institutional review board.

\section{Diabetes education curriculum}

DSME provided to study participants was patterned after the American Dietetic Association/Morrison Health Care protocols for type 1 and type 2 diabetes mellitus and was consistent with the requirements from the National Standards for DSME. ${ }^{17,18}$ Participants can receive either 1 hour of individual or 2 hours of group training dependent on patient preference for coaching, however, total education cannot exceed 10 total hours of instruction within a 12 month period. All education was provided by certified diabetes educators (CDE) who in addition are either a registered nurse or dietitian. Patients received instruction in: self-monitoring of glucose levels; diet/exercise education; medication management specifically for insulin dependent participants; motivation for self-management; diabetes related problem solving, and lifestyle changes to help reduce the risks and complications of diabetes. In addition, goal-setting was incorporated into the DSME to increase the patient's knowledge about the disease and how they can achieve control over their own health. These goals were specific (eg, exercise three times per week, consume $60 \mathrm{~g}$ carbohydrate per meal) and established by the patients in conjunction with the CDE. The overall intent of DSME is to provide patients with knowledge, skill, and ability to manage their disease, support informed decision making, self-care behaviors, problem-solving, and active collaboration with the health care team, and to improve clinical outcomes, health status, and quality of life. ${ }^{19}$

\section{Study measurement}

\section{Baseline characteristics}

As determined by billing codes, DSME patients were compared to non-DSME patients to assess whether differences in patient and clinic characteristics existed prior to the education visit and subsequent training. Baseline demographics included age, sex, race/ethnicity, and payer status. Education level for patients was not available. Clinical characteristics for the study cohort included chronic conditions such as heart failure, myocardial infarction, pulmonary disease, renal disease, Charlson comorbidity index ${ }^{19}$ (proxy marker for number of chronic conditions), and duration of diabetes history. Medication history for patients was incomplete and as such, was not included. Likewise, contextual clinic characteristics were collected for study patients including the type of primary care provider and the existence of team-based care programs such as PPC and MHI. Patients were assigned to a clinic through an imputation logic relying first on patient documentation as to their primary care provider. Secondarily, if a primary care provider was not identified, then the provider the patient has seen the most in the last 3 years.

\section{Study endpoints}

Change in the five part diabetes bundle measure score was the primary outcome of interest. For patients who participated in DSME training, $\mathrm{HbA}_{1 \mathrm{c}}$ levels were analyzed within 3 months prior and 2-6 months after first visit with a CDE occurred. For control patients, the first and last $\mathrm{HbA}_{1 \mathrm{c}}$ values within the study period were utilized with at least 90-180 days between the tests. To be coded as adherent to the five part diabetes bundle, patients are required to have met all elements of the bundle based on the thresholds listed in Table 1 .

\section{Statistical analysis}

Summary statistics were computed using frequencies and proportions for categorical variables which included means, medians, standard deviations, and ranges to describe the study population and clinic characteristics. Change in allor-none bundle achievement rate was evaluated using a chi-square analysis to test the null hypothesis that there was no difference in the proportion of patients who met the allor-none bundle before and after DSME. Change in $\mathrm{HbA}_{1}$ levels between control and DSME cohorts were compared using a Student's $t$-test testing the null hypothesis that mean change scores were not different between the two groups. We also tested the effect of time by computing the difference in means at baseline and follow-up for each group to determine if there was a statistical difference in $\mathrm{HbA}_{1 \mathrm{c}}$ over time. Logistic regression was performed to determine the odds of an improvement in the diabetes bundle and $\mathrm{HbA}_{1 \mathrm{c}}$ decrease after DSME visit. Multivariable models were used to adjust for demographic (age, sex) characteristics, baseline 
$\mathrm{HbA}_{1 \mathrm{c}} \%$, Charlson comorbidity index, duration of diabetes, and also clinic characteristics such as PPC or MHI programs that were determined to be possible confounders of achieving our hypothesis. Covariate adjustment was selected based on variables that were clinically meaningful confounders rather than statistically significant predictors of the study outcomes. To avoid multicollinearity, diagnostic testing was employed using graphical and numerical techniques within each model. For these analyses, a $P$-value $\leq 0.05$ was considered nominally statistically significant. All data were analyzed using Stata 12.0 (StataCorp LP, College Station, TX, USA).

\section{Results}

As documented in Figure 1, we identified 7,957 adults with diabetes from our internal diabetes registry during the study period. Of these, 1,287 patients were excluded based on $\mathrm{HbA}_{1 \mathrm{c}}$ values less than $6 \%$ or greater than $14 \%$. Another 1,949 patients were excluded due to having a primary care provider who was not employed by Intermountain Medical Group. Of those remaining $(\mathrm{n}=4,587), 384$ subjects $(9.0 \%)$ received DSME training. These case-patients were matched randomly at a 1:4 ratio with subjects with similar baseline $\mathrm{HbA}_{1 \mathrm{c}}$ values $(\mathrm{n}=1,536)$ who served as the control group.

Baseline demographic and clinical characteristics are summarized in Table 2. Over half (52.79\%) of the DSME group were female as compared to $47.9 \%$ in the control group $(P=0.10)$. Patients receiving DSME training tended to be younger than control patients (56.8 years versus 59.4 years; $P=0.002)$. There was no significant difference in insurance provider $(P=0.35)$ among the two groups, with over half of the payer mix being commercial providers. There was no difference in race/ethnicity, with the majority of patients in both groups being of Caucasian descent.

Patients with DSME tended to have more pulmonary disease $(P=0.02)$, less myocardial infarction prevalence $(P=0.02)$, and trended toward more renal disease $(P=0.07)$ as compared to patients in the control cohort. Yet, there was no difference in the prevalence of heart failure $(14.10 \%$ versus $14.90 \%, P=0.676)$, or Charlson comorbidity index score (4.60 versus $4.50 ; P=0.46$ ), a proxy marker for the number of chronic conditions a patient may have. Of note, patients with DSME tended to having shorter history of their diabetic disease with over $53 \%$ having a history of diabetes for less

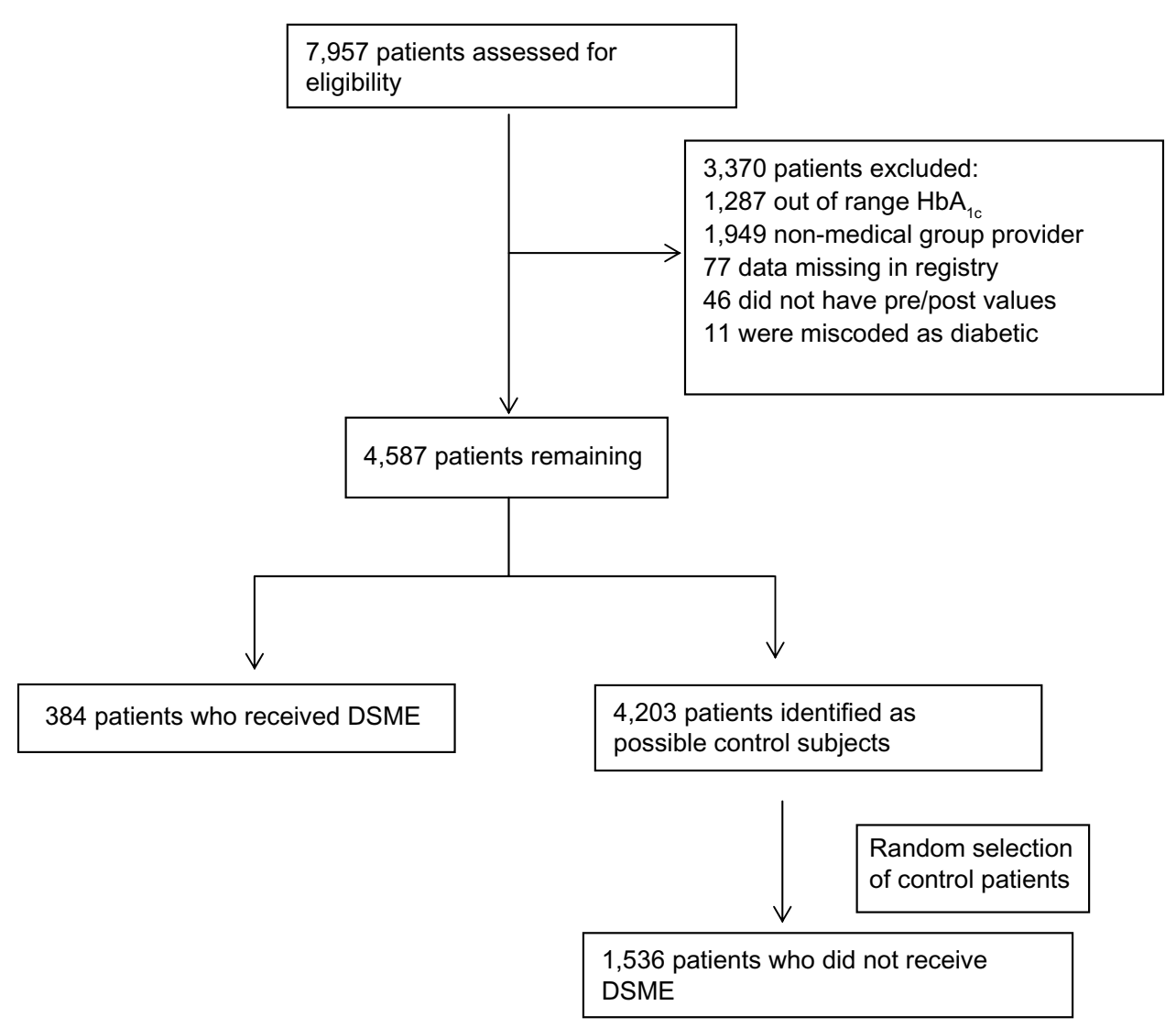

Figure I Flow diagram.

Abbreviation: DSME, diabetes self-management education. 
Table 2 Baseline demographics of study population

\begin{tabular}{|c|c|c|c|}
\hline & $\begin{array}{l}\text { Diabetic education } \\
\text { group, } n=384 \\
\text { Mean/SD or } \%\end{array}$ & $\begin{array}{l}\text { No diabetic education } \\
\text { group, } n=I, 536 \\
\text { Mean/SD or } \%\end{array}$ & $P$-value \\
\hline Female, \% & 52.8 & 47.9 & 0.095 \\
\hline Age at study start, years & $56.8 \pm 14.1$ & $59.4 \pm 14.3$ & 0.0017 \\
\hline \multicolumn{4}{|l|}{ Insurance, \% } \\
\hline Commercial & 50.9 & 54.4 & 0.351 \\
\hline Medicare & 38.0 & 37.8 & \\
\hline Medicaid & 5.9 & 5.0 & \\
\hline Self-pay & 5.01 & 2.9 & \\
\hline \multicolumn{4}{|l|}{ Race, \% } \\
\hline Caucasian (includes Hispanics) & 89.06 & 84.70 & 0.292 \\
\hline Black & 0.78 & I.II & \\
\hline Asian & 1.56 & 2.34 & \\
\hline Pacific Islander/Native American & 1.56 & 2.60 & \\
\hline Other & 7.03 & 9.24 & \\
\hline Heart failure, \% & 14.1 & 14.9 & 0.676 \\
\hline Pulmonary disease, \% & 45.1 & 38.6 & 0.021 \\
\hline Myocardial infarction, \% & 6.77 & 10.80 & 0.018 \\
\hline Renal disease, \% & $15.6 \mid$ & 12.17 & 0.071 \\
\hline Charlson comorbidity index & $4.60 \pm 2.91$ & $4.50 \pm 2.56$ & $0.46 I$ \\
\hline \multicolumn{4}{|l|}{ History of diabetes, \% } \\
\hline$<\mathrm{I}$ years & 1.82 & 2.80 & $<0.0001$ \\
\hline $1-4$ years & 52.08 & 37.24 & \\
\hline $5-9$ years & 20.83 & 27.02 & \\
\hline$\geq 10$ years & 25.26 & 32.94 & \\
\hline
\end{tabular}

Abbreviation: SD, standard deviation.

than 4 years as compared to $39 \%$ for patients in the control group $(P<0.0001)$.

Table 3 demonstrates that there was no significant difference among specialty type of primary care provider, with the majority of care falling within family medicine and internal medicine providers for case and control cohorts $(94.70 \%$ versus $95.80 \% ; P=0.56$ ) respectively. Of the clinics where our DSME cohort received care, $92.71 \%$ had the PPC program as compared to $71.48 \%$ for the control cohort $(<0.001)$. Of note, fewer clinics where case patients received care typically had MHI programs (86.46\%) as compared to the clinics attributed to patients without DSME $(90.30 \%)(P=0.03)$.

Figure 2A demonstrates that the diabetes bundle performance in patients in the DSME group was significantly improved over time when baseline and follow-up periods were compared. While there was no difference in baseline

Table 3 Clinic characteristics: study patients are attributed to provider/clinic

\begin{tabular}{|c|c|c|c|}
\hline & $\begin{array}{l}\text { Diabetic education } \\
\text { group, } n=384 \\
\text { Mean/SD or } \%\end{array}$ & $\begin{array}{l}\text { No diabetic education } \\
\text { group, } n=536 \\
\text { Mean/SD or } \%\end{array}$ & $P$-value \\
\hline \multicolumn{4}{|c|}{ Type of attributed provider, $\%$} \\
\hline Family medicine & 56.51 & 57.0 & 0.556 \\
\hline Internal medicine & 38.28 & 38.8 & \\
\hline Geriatric & 0.0 & 0.52 & \\
\hline Nurse practitioner & 3.64 & $2.4 I$ & \\
\hline Other & 1.56 & 1.30 & \\
\hline \multicolumn{4}{|c|}{ Mental health integration (\% clinics) } \\
\hline Yes & 86.46 & 90.30 & 0.03 \\
\hline No & 13.54 & 9.70 & \\
\hline \multicolumn{4}{|c|}{ Personalized primary care (\% clinics) } \\
\hline Yes & 92.71 & 71.48 & $<0.001$ \\
\hline No & 7.29 & 28.52 & \\
\hline
\end{tabular}

Abbreviation: SD, standard deviation. 
Table 4 Primary study outcomes

\begin{tabular}{|c|c|c|c|}
\hline & $\begin{array}{l}\text { Diabetic } \\
\text { education } \\
\text { group, } n=384 \\
\text { Mean/SD or \% }\end{array}$ & $\begin{array}{l}\text { No diabetic } \\
\text { education } \\
\text { group } n=536 \\
\text { Mean/SD or \% }\end{array}$ & $P$-value \\
\hline \multicolumn{4}{|l|}{$\mathrm{HbA}_{1 \mathrm{c}}, \%$} \\
\hline Baseline & $8.69 \pm 1.94$ & $8.58 \pm 1.82$ & 0.28 \\
\hline Follow-up & $7.33 \pm 1.39$ & $7.77 \pm 1.64$ & $<0.0001$ \\
\hline Difference ${ }^{b}$ & $-1.36 \pm 1.81$ & $-0.8| \pm I .7|$ & $<0.000$ I \\
\hline$P$-value & $<0.0001$ & $<0.0001$ & \\
\hline \multicolumn{4}{|c|}{ Five part diabetes bundle, $\%$ of adherent patients } \\
\hline Pre-study period & 14.58 & 12.43 & 0.261 \\
\hline Post-study period & 32.03 & 23.05 & $<0.000$ I \\
\hline$P$-value ${ }^{c}$ & $<0.0001$ & $<0.0001$ & \\
\hline
\end{tabular}

Notes: aComparison between groups; 'baseline to follow-up; 'comparison over time.

Abbreviation: SD, standard deviation.
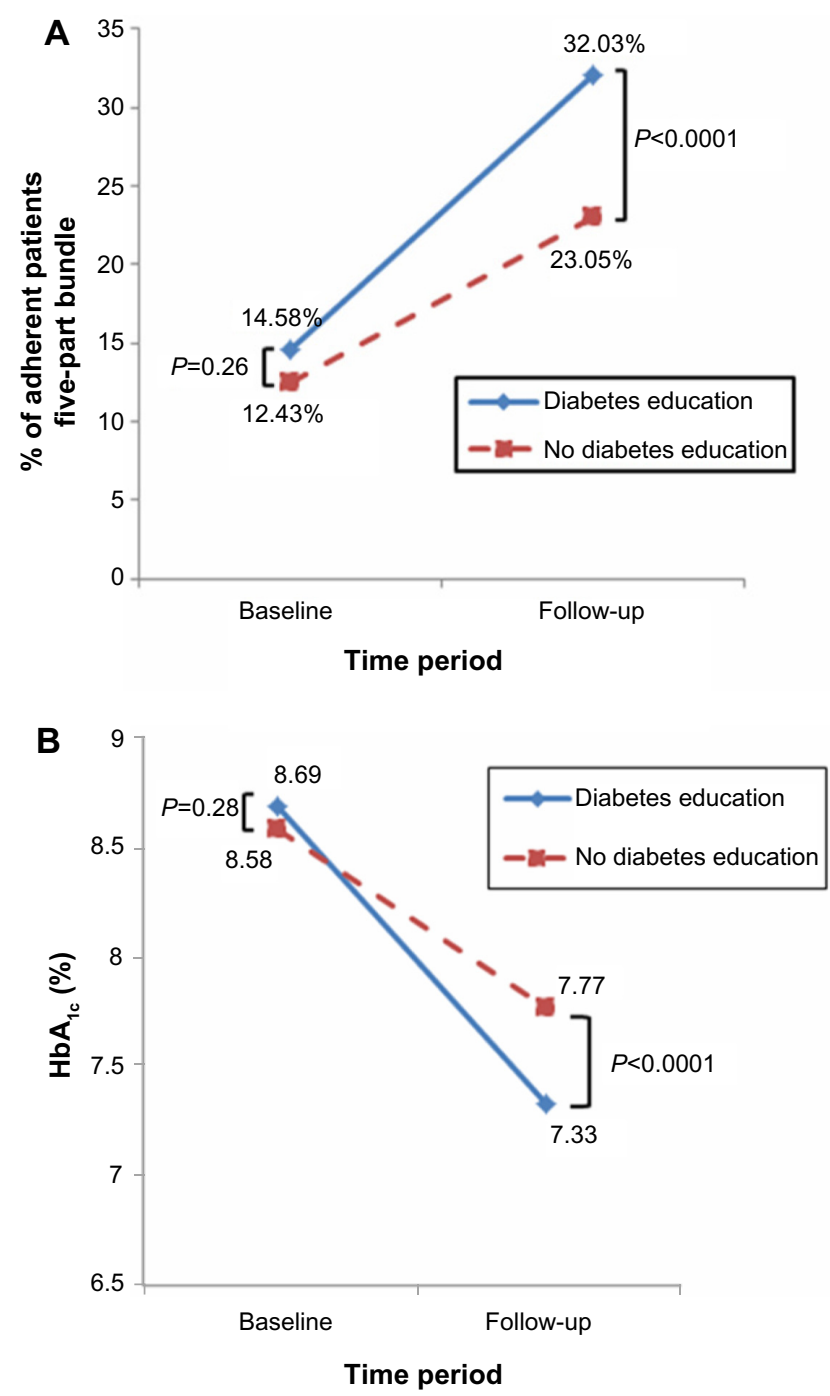

Figure 2 Primary study outcomes.

Notes: (A) Showing change in five part bundle (\%) for patients with and without diabetes education. (B) Showing change in $\mathrm{HbA}_{\mathrm{Ic}}$ for patients with and without diabetes education. compliance among the two groups $(14.58 \%$ compared to $12.43 \%)$, there was a significant difference when measured at follow-up (32.03\% compared to $23.05 \%$ ) and the magnitude of improvement (17.45\% versus $10.62 \%)$ was also highly significant $(P<0.0001)$. Similar results over time were seen for the difference in $\mathrm{HbA}_{1 \mathrm{c}}$ (Figure 2B). While there was no difference in baseline $\mathrm{HbA}_{1 \mathrm{c}}$ values among the two groups $(8.58 \%$ to $7.77 \%$ ), the magnitude of improvement in the DSME group was significantly greater than in the control group with the difference being $1.36 \%$ versus $0.81 \%$ $(P<0.0001)$ respectively (Table 4$)$. When one considers that a $1 \%$ decline in $\mathrm{HbA}_{1 \mathrm{c}}$ is associated with a $15 \%$ reduction in the risk of cardiovascular disease, these relatively small changes in $\mathrm{HbA}_{1 \mathrm{c}}$ translate to a clinically significant risk reduction for patients. ${ }^{20}$

The odds of achieving an improvement in bundle achievement over time were greater for patients with DSME, with almost a 1.5 fold difference as compared to those without education. Multivariate modeling displayed in Figure 3A and $\mathrm{B}$, demonstrate that even after adjusting for confounders such as age, sex, baseline $\mathrm{HbA}_{1 \mathrm{c}} \%$, duration of diabetes disease, Charlson comorbidity index, and clinic characteristics (existence of PPC and MHI programs within the clinics) patients with DSME had a subsequent significant increase in their achievement to the five part diabetes bundle (odds ratio $[\mathrm{OR}]=1.49$; confidence interval $[\mathrm{CI}]=1.11,2.001 ; P<0.008$ ) as well as improvement in their $\mathrm{HbA}_{1 \mathrm{c}} \%(\mathrm{OR}=2.80 ; \mathrm{CI}=2.05$, $3.83 ; P<0.0001)$ as compared to those without DSME.

\section{Discussion}

Management of patients with complex disease is one cornerstone of delaying and preventing complications and thus improving delivery of medical care, clinical outcomes, and appropriate utilization of health care resources. Although published evidence-based guidelines exist, care often fails to meet these guidelines due to barriers such as lack of time during office visits, patient adherence, and the struggle to stay current with new information and to recall specific instructions that are relevant to each patient. After previously re-designing their approach to managing patients with diabetes which includes a nine part all-or-none diabetes bundle, Geisinger Health System has demonstrated improvement not only in process measures and overall adherence to the bundle, but also clinical metrics such as $\mathrm{HbA}_{1 \mathrm{c}}<7 \%$, LDL $<100 \mathrm{mg} /$ $\mathrm{dL}$, and blood pressure $<130 / 80 \mathrm{mmHg}$ that have proven to be effective downstream in the management of diabetic complications. ${ }^{21,22}$ With over 146 distinct measures in diabetes 

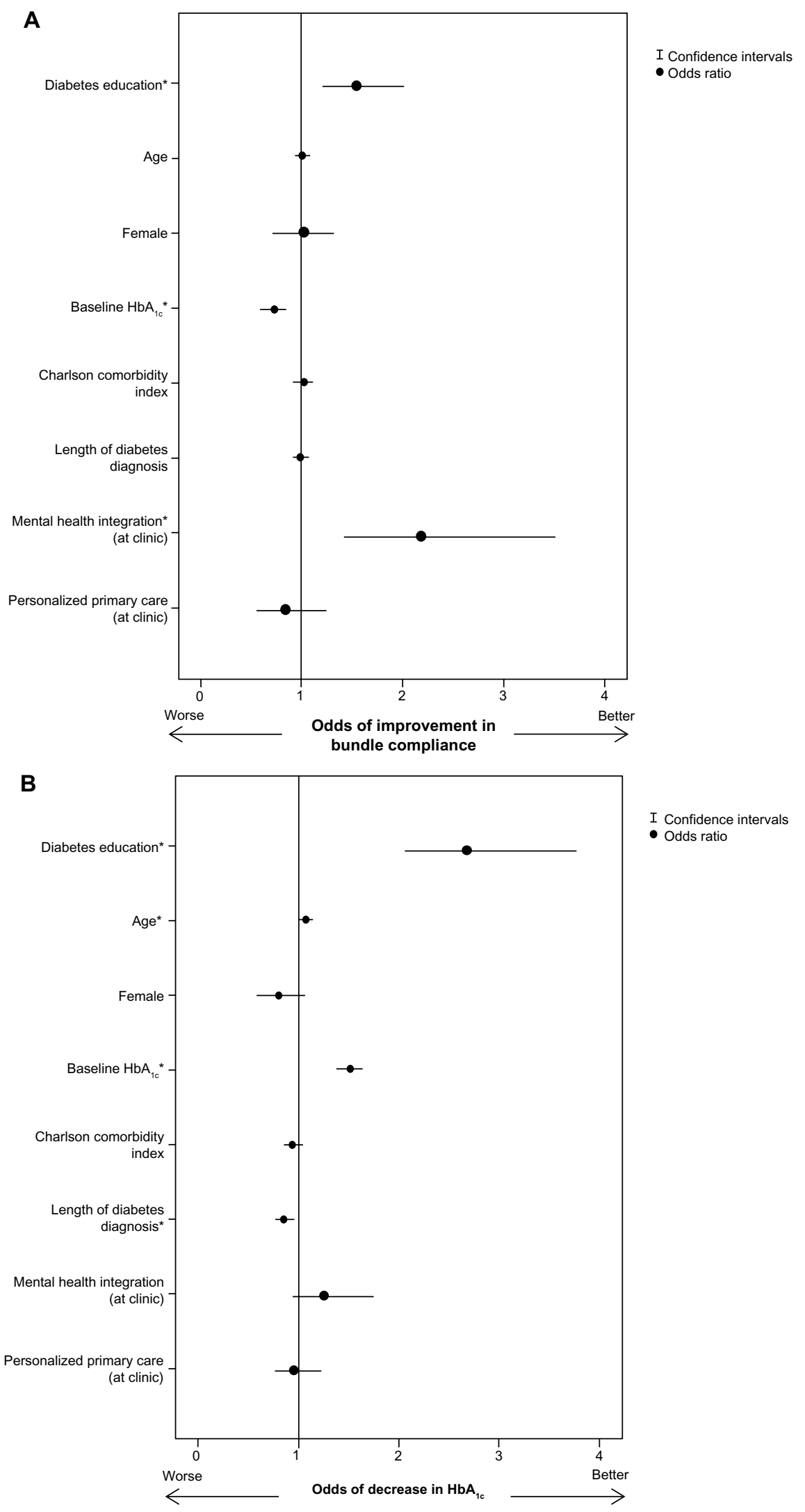

Figure 3 Odds ratios.

Notes: (A) Odds of DSME associated with an improvement in bundle adherence. (B) Odds of DSME associated with a decrease in $\mathrm{HbA}_{\mathrm{Ic}}{ }^{*}$ * tatistically significant: $P<0.00 \mathrm{I}$. Abbreviation: DSME, diabetes self-management education. 
care and differing results-based distinct combinations and organizations, ${ }^{21} \mathrm{IH}$ employs a five part bundle as an internal measurement tool to gauge intermediate quality outcomes associated with diabetes. Care that is more consistent and reliable has become a measure of how well we have been able to manage patients with diabetes, allowing for comparison to occur across clinics and providers at $\mathrm{IH}$ and with other groups nationally, leading to a more coordinated and accountable team-based care strategy. Finding innovative ways to improve the rate of bundle compliance has become the focal point of operational and clinical leadership at IH and our findings suggest that DSME can help achieve this, consistent with IH's efforts to reduce variability in care and improve consistent application of evidence-based medicine.

While a large body of literature supports the effectiveness of DSME in improving diabetes outcomes, ${ }^{23-25}$ much less evidence exists as to whether DSME could improve achievement of a five part diabetes bundle, a metric that has been created from evidence-based guidelines known to improve outcomes associated with diabetes complications. The findings of this study clearly support previous studies on improvement of $\mathrm{HbA}_{1 \mathrm{c}}$ levels with diabetes education beyond standard treatment alone, yet, also contribute to the limited body of knowledge surrounding methods to improve upon bundle achievement. ${ }^{11,25,26}$ The same literature also supports the cost benefit of DSME. An economic analysis conducted in 2000 by Klonoff and Schwartz reported that for every US \$1 spent on DSME, there was a net saving of \$0.44 to $\$ 8.76 .{ }^{27}$ In a systematic review conducted by Boren et al, 18 of 26 papers reported findings associating diabetes education (and disease management) with decreased costs, cost savings, cost effectiveness, or positive return on investment. ${ }^{14} \mathrm{~A}$ study by Duncan et al also published in 2009, documented that commercially insured members who receive diabetes education cost, on average, $5.7 \%$ less than members who do not participate in diabetes education and participating Medicare members cost significantly less (14\%). ${ }^{16}$ While DSME has been shown to be cost effective, results from a previously unpublished IH study showed that patients who meet all five components of the IH diabetes bundle may be less costly, even for those with multiple comorbidities.

While this study confirms the impact of DSME on improving $\mathrm{HbA}_{1 \mathrm{c}}$ it also demonstrates that patients receiving DSME within an ADA center are 1.5 times more likely to improve their five part diabetes bundle score within 6 months. This is an important and novel finding since improving bundle achievement tends to have an even greater clinical benefit to the patients and more efficiency in practice than just improving one key marker for diabetes such as $\mathrm{HbA}_{1 \mathrm{c}}{ }^{27}$ Each component of the bundle affects patient outcomes and potential complications a patient with diabetes may experience. Tracking multiple components through a bundle compliance rate is a unique opportunity for the clinical team to focus on multiple measures that when assessed together, address the holistic complexity of this disease.

It should be noted that while DSME increases adherence to the bundle, we also found that patients managed in clinics with MHI attained higher rates of bundle achievement compared to patients who did not have access to this resource. This is likely the result of team-based care focusing on mental health and wellness which may help diabetic patients to become more compliant with their overall treatment regimen; as well as improving awareness within the clinical team to be more in-tune with the broader needs of their patients. ${ }^{7}$ Since the Diabetes Attitudes Wishes and Needs 2 (DAWN2) study reported that psychosocial support is both critical and often inadequate with current DSME programs, the finding that MHI results in higher rates of bundle achievement merits further investigation. ${ }^{28}$

\section{Limitations}

While the methodology used in this study attempted to account for practice variation across the IH clinics where the patients received treatment for their diabetes, it might not account for all variation in practice which could affect the observed results. While we noted the impact of the MHI program on improving bundle compliance, this merits further study which is in progress. This study was a nested casecontrol study of patients identified within the IH diabetes registry and may not be sufficiently representative of all patients who had received DSME. The control group was carefully selected to make it comparable to the study group, but there may be inherent unaccounted differences that still remain which could affect the results observed. Since the IH diabetes registry does not distinguish between type 1 or type 2 diabetes mellitus, our study population may still include both types of the disease even though we limited our provider population to only primary care providers and did not consider those who delivered specialty care such as endocrinologists or diabetologists. In addition, we did not adjust for history or adherence to medication as this information was not consistently available for all patients. Similarly, we did not adjust for education levels between the two groups as this information was not available within our EDW. It should also be acknowledged that the study population was largely Caucasian and therefore, these results need to be evaluated 
with more ethnically diverse populations. Finally, outcomes of interest were only evaluated within 6 months of a DSME visit and longitudinal evaluation is warranted.

\section{Conclusion}

In summary, this study supports the existing literature on the effectiveness of DSME programs, and demonstrates that an ADA accredited DSME program at IH improves $\mathrm{HbA}_{1 \mathrm{c}}$ levels beyond standard care treatment for diabetes. More importantly, this study found that the DSME program significantly improved achievement of the five part diabetes bundle score, implying better overall outcomes for diabetic patients. Since many Patient Centered Medical Home demonstration projects are measuring improvement for diabetes on composite or bundle measures, including DSME as part of a Patient Centered Medical Home program seems to be an important strategy. ${ }^{29}$

In the future landscape of health care delivery, many health care systems will be at full financial risk for patients, receiving a per member per month payment to cover all expenditures. It is imperative that we seek the triple aim of improved health care delivery, enhanced patient outcomes, at the lowest appropriate cost. Future study is needed to evaluate the impact on resources and medical costs associated with the improvement on the bundle achievement for patients who receive DSME.

\section{Disclosure}

The authors have no conflicts of interest to disclose.

\section{References}

1. Cowie CC, Rust KF, Byrd-Holt DD, et al. Prevalence of diabetes and high risk for diabetes using $\mathrm{A}_{1 \mathrm{c}}$ criteria in the US population in 1988-2006. Diabetes Care. 2010;33(3):562-568.

2. Wild S, Roglic G, Green A, Sicree R, King H. Global prevalence of diabetes: estimates for the year 2000 and projections for 2030. Diabetes Care. 2004;27(5):1047-1053.

3. Blonde L. Benefits and risks for intensive glycemic control in patients with diabetes mellitus. Am J Med Sci. 2012;343(1):17-20.

4. Garber AJ. Obesity and type 2 diabetes: which patients are at risk? Diabetes Obes Metab. 2012;14(5):399-408.

5. intermountainhealthcare.org [homepage on the Internet]. Intermountain Healthcare. Available from: http://intermountainhealthcare.org/Pages/ home.aspx. Accessed October 28, 2013.

6. Reiss-Brennan B. Can mental health integration in a primary care setting improve quality and lower costs? A case study. J Manag Care Pharm. 2006;12(Supp1 2):14-20.

7. Reiss-Brennan B, Briot PC, Savitz LA, Cannon W, Staheli R. Cost and quality impact of Intermountain's mental health integration program. $J$ Healthc Manag. 2010;55(2):97-113; discussion 113-114.

8. intermountainhealthcare.org [homepage on the Internet]. Outpatient management of Adult Diabetes Mellitus: 2013 Update. Care Process Model 2013. Intermountain Healthcare. Available from: https://kr.ihc. com/ext/Dcmnt?ncid=51061827\&tfrm=default. Accessed October 28, 2013.
9. Nathan DM, Buse JB, Davidson MB, et al. Medical management of hyperglycemia in type 2 diabetes: a consensus algorithm for the initiation and adjustment of therapy: a consensus statement of the American Diabetes Association and the European Association for the Study of Diabetes. Diabetes Care. 2009;32(1):193-203.

10. American Diabetes Association. Standards of Medical Care in Diabetes 2010. Diabetes Care. 2010;33(Suppl 1):S11-S61.

11. Martin AL, Lipman RD. The future of diabetes education: expanded opportunities and roles for diabetes educators. Diabetes Educ. 2013;39(4):436-446.

12. Morrison F, Shubina M, Turchin A. Lifestyle counseling in routine care and long-term glucose, blood pressure, and cholesterol control in patients with diabetes. Diabetes Care. 2012;35(2):334-341.

13. Gregg EW, Chen H, Wagenknecht LE, et al. Association of an intensive lifestyle intervention with remission of type 2 diabetes. JAMA. 2012;308(23):2489-2496.

14. Boren SA, Fitzner KA, Panhalkar PS, Specker JE. Costs and benefits associated with diabetes education: a review of the literature. Diabetes Educ. 2009;35(1):72-96.

15. Anderson JW, Kendall CW, Jenkins DJ. Importance of weight management in type 2 diabetes: review with meta-analysis of clinical studies. J Am Coll Nutr. 2003;22(5):331-339.

16. Duncan I, Birkmeyer C, Coughlin S, Li QE, Sherr D, Boren S. Assessing the value of diabetes education. Diabetes Educ. 2009;35(5):752-760.

17. New York State Department of Health. 2011/2012 HEDIS Quality Assurance Reporting Requirements. Available from: http://www.health. ny.gov/health_care/managed_care/qarrfull/qarr_2011/docs/qarr_specifications_manual_2011.pdf. Accessed September 4, 2014.

18. Christensen NK, Steiner J, Whalen J, Pfister R. Contribution of medical nutrition therapy and diabetes self-management education to diabetes control as assessed by hemoglobin $\mathrm{A}_{1 \mathrm{c}}$. Diabetes Spectrum. 2000;13(2):72.

19. Quan H, Li B, Couris CM, et al. Updating and validating the Charlson comorbidity index and score for risk adjustment in hospital discharge abstracts using data from 6 countries. Am J Epidemiol. 2011;173(6): 676-682.

20. Holman RR, Sourij H, Califf RM. Cardiovascular outcome trials of glucose-lowering drugs or strategies in type 2 diabetes. Lancet. 2014;383(9933):2008-2017.

21. Bloom FJ Jr, Graf T, Anderer T, Stewart WF. Redesign of a diabetes system of care using an all-or-none diabetes bundle to build teamwork and improve intermediate outcomes. Diabetes Spectrum. 2010;23: $165-169$.

22. Weber V, Bloom F, Pierdon S, Wood C. Employing the electronic health record to improve diabetes care: a multifaceted intervention in an integrated delivery system. $J$ Gen Intern Med. 2008;23(4):379-382.

23. Warsi A, Wang PS, LaValley MP, Avorn J, Solomon DH. Selfmanagement education programs in chronic disease: a systematic review and methodological critique of the literature. Arch Intern Med. 2004;164(15):1641-1649.

24. Norris SL, Lau J, Smith SJ, Schmid CH, Engelgau MM. Self-management education for adults with type 2 diabetes: a meta-analysis of the effect on glycemic control. Diabetes Care. 2002;25(7):1159-1171.

25. Deakin T, McShane CE, Cade JE, Williams RD. Group based training for self-management strategies in people with type 2 diabetes mellitus. Cochrane Database Syst Rev. 2005(2):CD003417.

26. Christensen NK, Williams P, Pfister R. Cost savings and clinical effectiveness of an extension service diabetes program. Diabetes Spectrum. 2004;17(3):171-175.

27. Klonoff DC, Schwartz DM. An economic analysis of interventions for diabetes. Diabetes Care. 2000;23(3):390-404.

28. Peyrot M, Burns KK, Davies M, et al. Diabetes Attitudes Wishes and Needs 2 (DAWN2): a multinational, multi-stakeholder study of psychosocial issues in diabetes and person-centred diabetes care. Diabetes Res Clin Pract. 2013;99(2):174-184.

29. Bojadzievski T, Gabbay RA. Patient-centered medical home and diabetes. Diabetes Care. 2011;34(4):1047-1053. 


\section{Publish your work in this journal}

The Journal of Multidisciplinary Healthcare is an international, peerreviewed open-access journal that aims to represent and publish research in healthcare areas delivered by practitioners of different disciplines. This includes studies and reviews conducted by multidisciplinary teams as well as research which evaluates the results or conduct of such teams or

healthcare processes in general. The journal covers a wide range of areas and welcomes submissions from practitioners at all levels, from all over the world. The manuscript management system is completely online and includes a very quick and fair peer-review system. Visit http://www.dovepress.com/testimonials.php to read real quotes from published authors.

Submit your manuscript here: http://www.dovepress.com/journal-of-multidisciplinary-healthcare-journal 